Article

\title{
Detection of Gadolinium in Surrogate Nuclear Fuel Debris Using Fiber-Optic Laser-Induced Breakdown Spectroscopy under Gamma Irradiation
}

\author{
Ryuzo Nakanishi ${ }^{1,2, *(\mathbb{D}}$, Morihisa Saeki ${ }^{1,2}$, Ikuo Wakaida ${ }^{2}$ and Hironori Ohba ${ }^{1,2, *}$ \\ 1 Quantum Beam Science Research Directorate, National Institutes for Quantum and Radiological Science and \\ Technology (QST), 2-4 Shirakata, Tokai-mura, Naka-gun, Ibaraki 319-1106, Japan; saeki.morihisa@qst.go.jp \\ 2 Collaborative Laboratories for Advanced Decommissioning Science, Japan Atomic Energy Agency (JAEA), \\ Tokai, Ibaraki 319-1195, Japan; wakaida.ikuo@jaea.go.jp \\ * Correspondence: nakanishi.ryuzo@qst.go.jp (R.N.); ohba.hironori@qst.go.jp (H.O.)
}

Received: 2 November 2020; Accepted: 14 December 2020; Published: 16 December 2020

\begin{abstract}
Fiber-optic laser-induced breakdown spectroscopy (FO-LIBS) was applied to a qualitative and quantitative analysis of gadolinium $(\mathrm{Gd})$ in mixed oxide samples, simulating nuclear fuel debris in the damaged reactors of the Fukushima Daiichi Nuclear Power Station. The surrogate debris was prepared from mixed oxide materials containing $\mathrm{Gd}_{2} \mathrm{O}_{3}$, with varying $\mathrm{Gd}$ concentrations. The emission spectra of the surrogate debris show that the optical emission lines at $501.5 \mathrm{~nm}$ and $510.3 \mathrm{~nm}$ are suitable for $\mathrm{Gd}$ detection in the nuclear fuel debris. LIBS measurements were further performed under gamma irradiation $(0-10 \mathrm{kGy} / \mathrm{h})$, resulting in a decrease in spectral intensities due to radiation-induced damage to the optical fiber. For quantification of $\mathrm{Gd}$, robust calibration curves against gamma irradiation were established from the intensity ratio of $\mathrm{Gd}(501.5 \mathrm{~nm}) / \mathrm{Ce}(474.5 \mathrm{~nm})$ emission lines, yielding the limits of detection for $\mathrm{Gd}$ in the range of $0.03-0.08 \mathrm{wt} \%$. These results demonstrate that FO-LIBS is a potential tool for in situ and remote analysis of nuclear fuel debris.
\end{abstract}

Keywords: laser-induced breakdown spectroscopy; fiber-optic; rare earth elements; nuclear fuel debris; gamma irradiation

\section{Introduction}

Since the accident at the Fukushima Daiichi Nuclear Power Station (F1-NPS) in 2011, a great deal of effort has been devoted to the decommissioning of F1-NPS. The biggest challenge facing this process is the retrieval of the nuclear fuel debris, which was formed in the reactor vessels during the meltdown accident [1]. The fuel debris is presumed to contain uranium oxide $\left(\mathrm{UO}_{2}\right)$ from the fuel itself, zirconium ( $\mathrm{Zr}$ ) from the cladding, and stainless steel ( $\mathrm{Fe}, \mathrm{Ni}, \mathrm{Cr}$ ) from the surrounding structural material, while the actual composition ratio may vary depending on where the debris was formed $[2,3]$. Besides those elements, another key element is gadolinium $(\mathrm{Gd})$. A trace amount of gadolinium oxide $\left(\mathrm{Gd}_{2} \mathrm{O}_{3}\right)$ was incorporated into some of the fuel rods to control fuel reactivity efficiently; $\mathrm{Gd}$ acts as a burnable absorber of thermal neutrons with the aid of the high neutron absorption cross-sections of ${ }^{155} \mathrm{Gd}$ and ${ }^{157} \mathrm{Gd}$ isotopes $[4,5]$. The relative abundance of $\mathrm{Gd}$ in the debris is an important factor for criticality control of the debris and a risk assessment of the retrieval process. Although it is crucial to determine its elemental compositions, the nuclear fuel debris is currently inaccessible and has yet to be identified because of the high radioactivity in the reactor vessels. Thus, there is a compelling need for methods to remotely analyze the debris and detect the above elements in a high-radiation field.

Laser-induced breakdown spectroscopy (LIBS) is an elemental analysis technique based on plasma emission spectroscopy [6-8]. In LIBS, the output of a pulsed laser is focused onto the target material to 
generate a luminous plasma. The optical emission from the plasma is then collected with a spectrometer for qualitative and quantitative elemental analysis. Because LIBS allows us to perform remote and rapid measurements with little or no sample preparation, there have been continuous efforts to apply LIBS to nuclear material analysis [9-12]. In particular, fiber-optic LIBS (FO-LIBS), which employs fiber optics to deliver laser light and collect plasma light [13], is considered suitable for the direct analysis of radioactive debris because it provides flexible access to a variety of samples in hazardous environments. We recently developed a portable FO-LIBS system originally aimed at the remote analysis of underwater samples in a harsh environment [14]. While several of our studies have demonstrated the capability of our system for analyzing various samples [14-16], measurements in a radiation field have yet to be explored. Therefore, further examination is necessary for the FO-LIBS approach to the analysis of the nuclear fuel debris.

This paper reports on the application of our FO-LIBS system for the identification and quantification of $\mathrm{Gd}$ in surrogate nuclear fuel debris under gamma irradiation. As real fuel debris is not available as a sample, the LIBS measurements were performed using surrogate debris synthesized from mixed oxide materials containing $\mathrm{Gd}, \mathrm{Ce}, \mathrm{Zr}$, and Fe. Cerium was employed as a surrogate for uranium based on the similarity of their electronic structures [17]. Detection of Gd in such complex materials is challenging because of the presence of a high density of spectral lines from the rare earth elements that severely interfere with each other $[18,19]$. Another aspect to consider is the damage to the optical components of the LIBS system caused by gamma irradiation; exposure to gamma rays deteriorates the optical throughput, eventually hindering stable LIBS measurements. This study aims to reveal Gd emission lines applicable to Gd identification in the nuclear fuel debris and obtain calibration curves that will prove robust against gamma irradiation.

\section{Materials and Methods}

The surrogate debris was synthesized from powder mixtures of $\mathrm{Gd}_{2} \mathrm{O}_{3}, \mathrm{CeO}_{2}, \mathrm{ZrO}_{2}$, and $\mathrm{Fe}_{2} \mathrm{O}_{3}$ to resemble the nuclear fuel debris. All materials were used as received from the supplier (RARE METALLIC, Tokyo, Japan). The mixtures were prepared so that the mass fractions of Ce, Zr, and Fe conformed to the predicted values for the nuclear fuel debris [3], with the various concentrations of $\mathrm{Gd}$. Each mixture $(0.5 \mathrm{~g})$ was compressed under hydrostatic pressure $(10 \mathrm{kN})$ into a pellet with an $8 \mathrm{~mm}$ diameter and sintered at $1375^{\circ} \mathrm{C}$ for $5 \mathrm{~h}$. The resulting mass fractions of each element per sample are listed in Table 1.

Table 1. Elemental composition ( $w \mathrm{t} \%$ ) of the surrogate nuclear fuel debris.

\begin{tabular}{ccccc}
\hline Sample & Ce & Zr & Fe & Gd \\
\hline$\# 1$ & 44.6 & 24.0 & 8.3 & 0.87 \\
$\# 2$ & 44.8 & 24.1 & 8.3 & 0.44 \\
$\# 3$ & 44.9 & 24.2 & 8.3 & 0.22 \\
$\# 4$ & 45.0 & 24.2 & 8.3 & 0.09 \\
$\# 5$ & 45.1 & 24.2 & 8.3 & 0.00 \\
\hline
\end{tabular}

Figure 1a presents a schematic of the portable FO-LIBS setup used in this study. This setup was slightly modified from the previous version of our FO-LIBS system [14]: a Q-switched Nd:YAG laser (Minilite II, Amplitude, Milpitas, CA, USA) was mounted for the single-pulse operation, and the Czerny-Turner spectrometer was replaced by an Echelle-type spectrometer (EMU-65, Catalina Scientific, Tucson, AZ, USA) for wide spectral coverage. The configuration was installed in an aluminum frame with dimensions of $500 \times 700 \times 880$ (see photograph in Figure 1b). The laser output $(1064 \mathrm{~nm}, 6 \mathrm{~ns}$ pulses operating at $5 \mathrm{~Hz}$ ) was coupled into a high-OH optical fiber (S.1000/1100, Fujikura, Japan; length: $5 \mathrm{~m}$; core diameter: $1 \mathrm{~mm}$; NA: $0.12, \mathrm{OH}$ in the core: $\sim 1000 \mathrm{ppm}$, fluorine in the clad: $4 \mathrm{wt} \%$ ) using a convex lens $(f=125 \mathrm{~mm})$ at a coupling box evacuated to a pressure of $90 \mathrm{kPa}$. The laser light was then delivered to a home-built probe head. The laser beam $(10 \mathrm{~mJ} /$ pulse $)$ was focused 
onto the sample surface with $f=40 \mathrm{~mm}$ and $f=12.5 \mathrm{~mm}$ lens pairs equipped on the probe head. The diameter of the laser spot was $350 \mu \mathrm{m}$. The optical emission was collected by the same optics for the laser delivery, transported to another optical fiber using a pierced mirror at the fiber coupling box, and fed into the Echelle spectrometer equipped with an electron multiplying charge coupled device (EMCCD) camera (FA285-CL, Raptor Photonics, Larne, UK). Spectral detection was synchronized with the laser pulse using a digital delay generator (Model 9214, Quantum Composers, Bozeman, MT, USA); the EMCCD camera was triggered at a delay of $1 \mu$ s to the laser irradiation, which yielded the best signal-to-background ratio (SBR) for the Gd emission lines. The exposure time was set to $2 \mu \mathrm{s}$; the longer exposure resulted in the emergence of highly complex profiles because optical emissions from the molecular species dominated the spectra. Each spectrum was acquired for 500 laser shots. To gain a calibration curve at a given dose rate, five spectra were recorded for each sample.

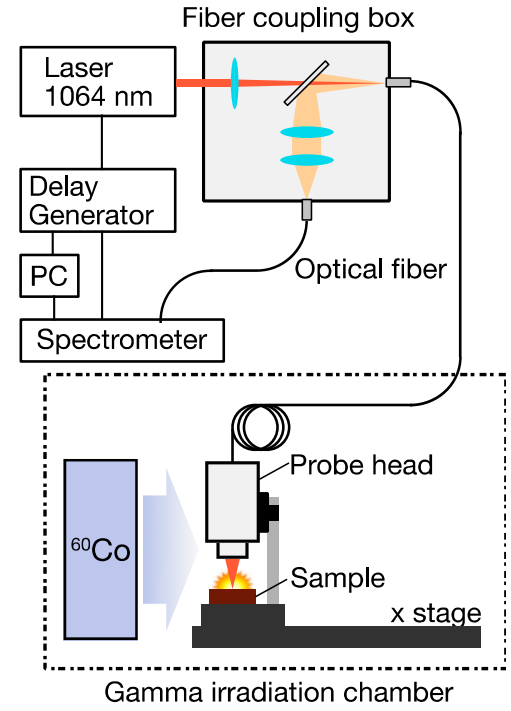

(a)

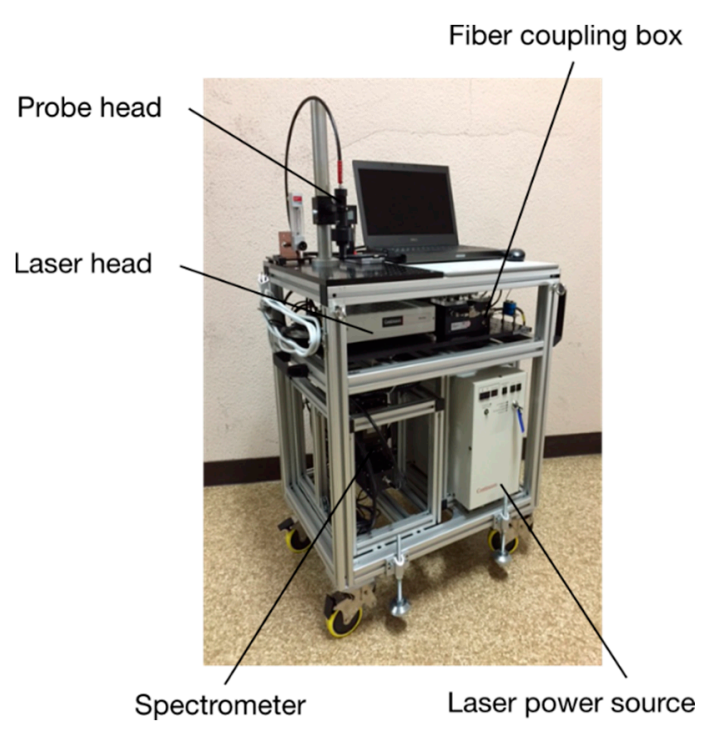

(b)

Figure 1. Overview of the experimental setup. (a) Schematic of the fiber-optic laser-induced breakdown spectroscopy (FO-LIBS) system. (b) Photograph of the FO-LIBS apparatus.

The influence of a given radiation field was investigated at the ${ }^{60} \mathrm{Co}$ gamma irradiation facility at Takasaki Advanced Radiation Research Institute, National Institutes for Quantum and Radiological Science and Technology (QST) in Japan. The dose rates tested in the present work were 0, 0.8, and $10 \mathrm{kGy} / \mathrm{h}$, which were controlled by adjusting the distance between the ${ }^{60} \mathrm{Co}$ emitter and the probe head installed on a motorized linear stage. The irradiation was performed in ambient air at room temperature.

\section{Results and Discussion}

Figure 2 displays the representative LIBS spectra of the surrogate debris (sample \#5) measured before and during gamma irradiation. The spectrum during irradiation was recorded when the accumulated dose reached $5.4 \mathrm{kGy}$ at $10 \mathrm{kGy} / \mathrm{h}$. The spectral profiles appear congested, originating from the prominent lines of $\mathrm{Ce}$ and $\mathrm{Zr}$, along with the minor lines of $\mathrm{Fe}$ and $\mathrm{N}$. As shown in Figure 2, gamma irradiation decreased the LIBS signal, particularly in the UV-Vis region $(\lambda<800 \mathrm{~nm})$. The wavelength range of the degradation was consistent with that observed in the transmission attenuation of the optical fiber induced by gamma irradiation. Figure 3a shows a spectrum of the transmission loss of the optical fiber induced by gamma irradiation. It was measured in a separate experiment using a brand-new fiber, a halogen lamp (USS-600, Labsphere, North Sutton, NH, USA), and multichannel spectrometers (EPP2000-HR and BLUE-WAVE, StellarNet, Tampa, 
FL, USA). The decrease in the LIBS signal was thus attributed to the damage to the optical fiber. Radiation-induced damage in optical fibers has been the target of several studies [20-24]; in particular, the gamma-ray dissociates $\mathrm{Si}-\mathrm{O}$ bonds of silica in the fiber, which yields various types of radical species playing the role of color centers. The formation of these color centers attenuates the optical transmission of the fiber, particularly in the UV-Vis region [24]. By contrast, transmittance at the infrared region proved resistant to gamma irradiation (Figure 3a). Accordingly, transmission at $1064 \mathrm{~nm}$ (the wavelength of the excitation laser) remained almost intact, as shown in the temporal change of the transmission loss at $1064 \mathrm{~nm}$ (Figure 3b).

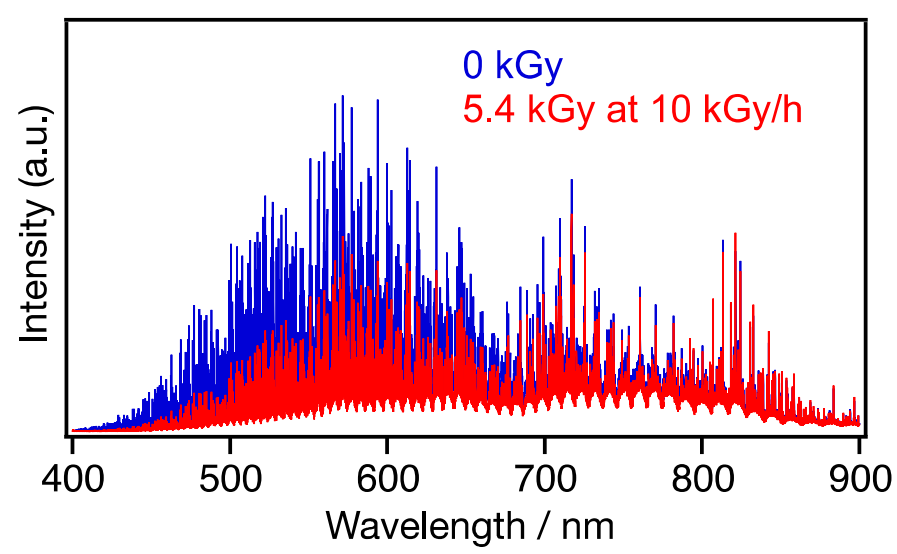

Figure 2. Emission spectra of the surrogate nuclear fuel debris with and without gamma irradiation at a dose rate of $10 \mathrm{kGy} / \mathrm{h}$.

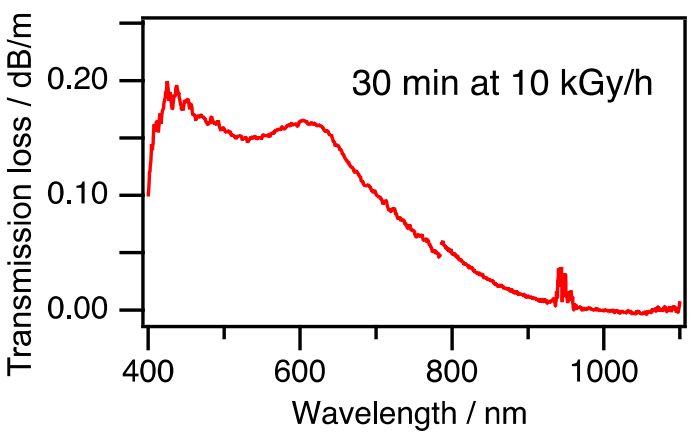

(a)

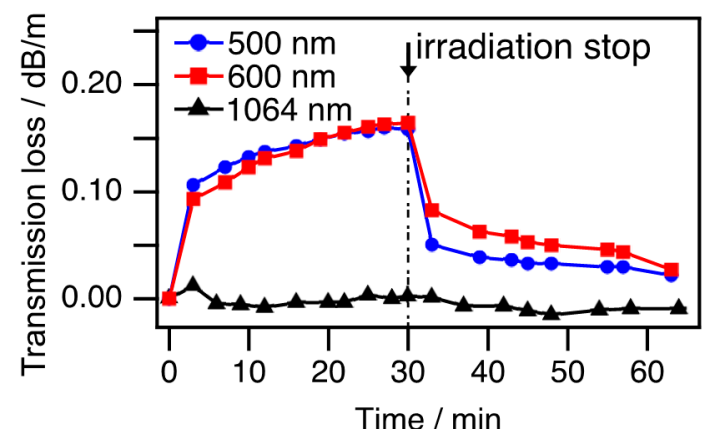

(b)

Figure 3. Transmission loss of the optical fiber induced by gamma irradiation (10 kGy/h). (a) Spectrum of transmission loss after $30 \mathrm{~min}$ irradiation. The fluctuations at around $950 \mathrm{~nm}$ originated from the inherently low transmittance of the high-OH fiber due to the strong photoabsorption of $\mathrm{OH}$.

(b) Time evolution of the transmission loss at $500 \mathrm{~nm}$ (blue circle), $600 \mathrm{~nm}$ (red square), and $1064 \mathrm{~nm}$ (black triangle). The gamma irradiation was stopped at $30 \mathrm{~min}$.

It was also found that the LIBS spectra recorded immediately before and after stopping the irradiation $(10 \mathrm{kGy} / \mathrm{h})$ showed almost identical profiles (not shown here). This indicates that the gamma radiation field scarcely affected the properties of the laser-induced plasma, as expected from the weakly ionizing feature of the gamma rays $(1.17$ and $1.33 \mathrm{MeV})$ from ${ }^{60} \mathrm{Co}$. As the transmittance of the fiber started recovering after the irradiation was halted (Figure 3b), the LIBS signal gradually increased. The experiments for obtaining the calibration curves described below repeated the LIBS measurements and the sample change. When the samples changed, gamma irradiation was stopped by removing the ${ }^{60} \mathrm{Co}$ emitter. As a result, the fiber transmittance underwent alternating degradation and recovery throughout the LIBS measurements, further perturbing the detected spectral intensities. 
The Gd spectral lines applicable to Gd identification were determined by comparing the LIBS spectra of samples \#1(Gd: $0 \mathrm{wt} \%)$ and \#5(Gd: $0.87 \mathrm{wt} \%)$, measured without gamma irradiation. The obtained spectra contained the optical emissions from neutral Gd (Gd-I lines). In contrast, the ionic lines (Gd-II lines) were very weak, probably because the plasma temperature was not high enough to populate a sufficient amount of $\mathrm{Gd}$ in its ionic state at a $1 \mu$ s delay time between the laser irradiation and the spectral detection. Although the numerous Gd emission lines are present at $\lambda<700 \mathrm{~nm}$ [25], most of them suffered from severe spectral interference with the lines of the other elements in the surrogate debris. As seen in Figure 4, the lines at 501.5 and $510.3 \mathrm{~nm}$ are well separated from the others. Those lines are not associated with resonance transitions, minimizing the influence of self-absorption. Note that the emission lines of uranium are absent in the close vicinity of those Gd lines [25,26], which can therefore be used for Gd identification.

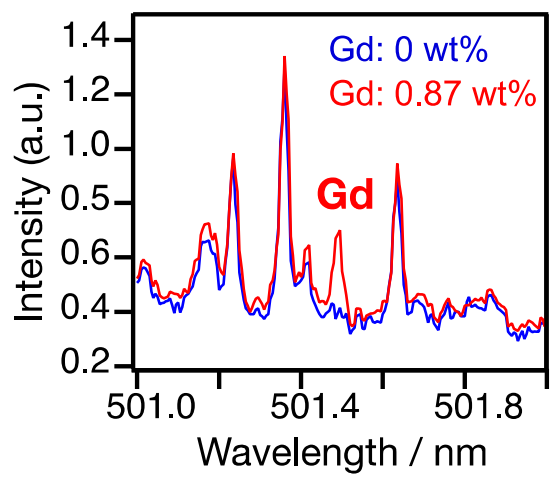

(a)

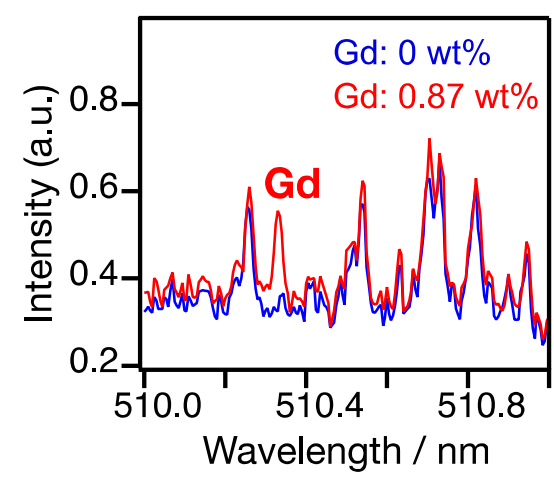

(b)

Figure 4. Emission spectra of surrogate nuclear fuel debris in the neighborhood of Gd lines at (a) $501.5 \mathrm{~nm}$ and (b) $510.3 \mathrm{~nm}$.

The absolute intensities of those lines were not suitable for Gd quantification in the present work because they were not scaled with the concentration of $\mathrm{Gd}$ due to the disturbance from gamma irradiation. In addition, even in the five repeated measurements for a given sample, the relative standard deviation (RSD) values became high at a high dose rate. For example, the RSD of the Gd $501.5 \mathrm{~nm}$ line of sample \#5 was evaluated as $8.9 \%, 16.2 \%$, and $27.5 \%$ at $0,0.8$, and $10 \mathrm{kGy} / \mathrm{h}$, respectively. To derive Gd calibration curves under such fluctuating conditions, the intensity ratio of $\mathrm{Gd}$ and $\mathrm{Ce}$ lines were employed as a measure of $\mathrm{Gd}$ concentration rather than the absolute intensities. The pair of spectral lines were selected as the $501.5 \mathrm{~nm}$ line $(\mathrm{Gd})$ and $474.5 \mathrm{~nm}$ line (Ce). This selection is based on the similarity between the upper-level energies for the two emission lines: $3.58 \mathrm{eV}$ for the $\mathrm{Gd} 501.5 \mathrm{~nm}$ line and $3.53 \mathrm{eV}$ for the Ce $474.5 \mathrm{~nm}$ line $[25,26]$. This mitigates the influence of the fluctuation of the plasma conditions [27]. The intensity ratios were calculated using the peak heights with baseline subtraction, yielding lower RSDs than the absolute spectral intensities: $5.0 \%, 1.8 \%$, and $5.0 \%$ at $0,0.8$, and $10 \mathrm{kGy} / \mathrm{h}$, respectively.

Figure 5 presents the calibration curves obtained from the $\mathrm{Gd}(501.5 \mathrm{~nm}) / \mathrm{Ce}(474.5 \mathrm{~nm})$ intensity ratios, showing good linearity with the Gd concentrations. The results of the linear regression are summarized in Table 2. The limits of detection (LOD) of Gd were calculated as $0.03-0.08 \mathrm{wt} \%$ (Table 2) using the expression of LOD $=3 \sigma / b$, where $\sigma$ represents the standard deviation in the blank sample and $b$ represents the slope of the curve. The similarity of the calibration curves in Figure 5 indicates that the variation of the dose rate exerts only a slight influence on the ratios of the spectral intensities, demonstrating the feasibility of the FO-LIBS in analyzing gadolinium-containing debris in radiation environments. As the present method relies on line intensity ratios, prior knowledge of Ce concentration is required to determine the $\mathrm{Gd}$ content. It is therefore more favorable to simultaneously measure the absolute concentrations of these elements. On the basis of the finding that the line intensities ratios 
were robust to the radiation field, more elaborate methods such as calibration-free analysis [28,29] may be implemented to derive the absolute concentrations of $\mathrm{Gd}$ and the other constituent elements in the debris.

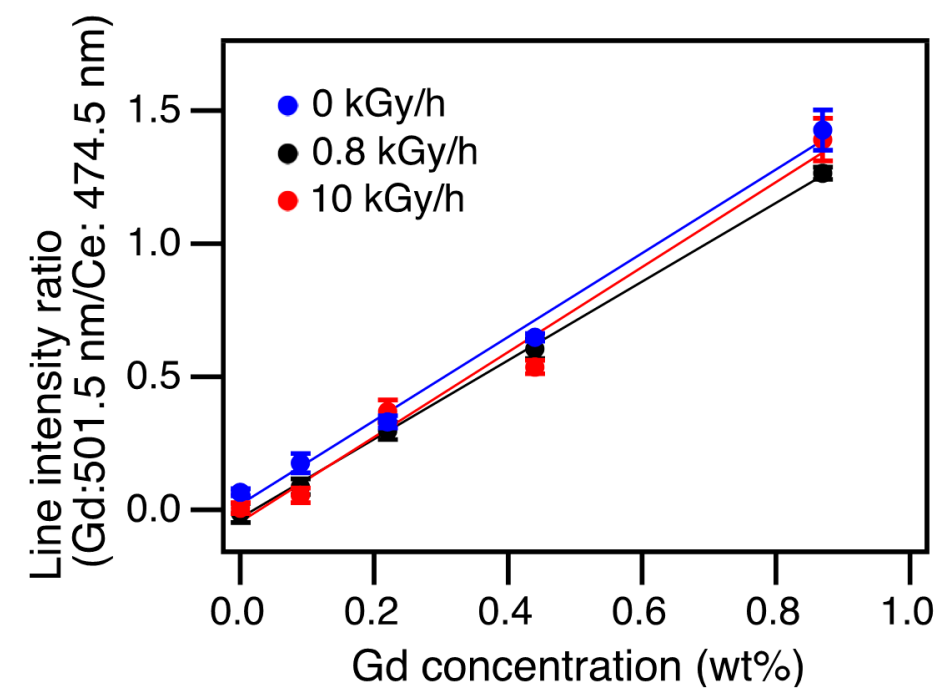

Figure 5. Calibration curves derived from the intensity ratio of $\mathrm{Gd} 501.5 \mathrm{~nm} / \mathrm{Ce} 474.5 \mathrm{~nm}$ lines. The $R^{2}$ values and fitting parameters are listed in Table 2.

Table 2. $R^{2}$ values and fitting parameters for Gd calibration curves. $b$ : slopes of the curves, $a$ : intercepts.

\begin{tabular}{ccccc}
\hline Dose Rate (kGy/h) & $\boldsymbol{R}^{\mathbf{2}}$ & $\boldsymbol{b}$ & $\boldsymbol{a}$ & LOD (wt \%) \\
\hline 0 & 0.993 & 1.573 & 0.020 & 0.027 \\
0.8 & 0.999 & 1.481 & -0.031 & 0.075 \\
10 & 0.980 & 1.595 & -0.045 & 0.039 \\
\hline
\end{tabular}

\section{Conclusions}

To explore the FO-LIBS approach in the analysis of nuclear material in a radiation field, Gd detection in surrogate nuclear fuel debris was examined under gamma irradiation $(0-10 \mathrm{kGy} / \mathrm{h})$ using a portable FO-LIBS apparatus developed by our group. The LIBS spectra of the surrogate debris revealed that the emission lines of $\mathrm{Gd}$ at $501.5 \mathrm{~nm}$ and $510.3 \mathrm{~nm}$ are potential candidates for the identification of $\mathrm{Gd}$ in real fuel debris. The observed spectral intensities were diminished upon gamma irradiation as a result of radiation-induced damage to the optical fiber, while the plasma characteristics were hardly affected by the gamma radiation field. Calibration curves were established from the intensity ratio of $\mathrm{Gd}(501.5 \mathrm{~nm})$ and Ce $(474.5 \mathrm{~nm})$ emission lines, exhibiting good linearity with the Gd concentrations. The LOD of Gd was calculated to be less than $0.1 \mathrm{wt} \%$, regardless of the radiation dose rate.

This study highlights the capability of FO-LIBS to perform in situ and in the remote analysis of nuclear material in a high-radiation field. Furthermore, the combination of our probing system with a robotic arm could improve accessibility to remote samples. Inspection of the damaged reactor vessels requires a longer fiber-optic cable, which significantly attenuates the delivered laser energy by absorption and scattering in the fiber $[9,13]$. As the use of intense laser pulses in compensation may damage the fiber, the laser fluence at the focal spot will be eventually limited, thereby reducing the LIBS signal intensity. This limitation will be overcome by combining FO-LIBS with a giant-pulse microchip laser [30]; a lasing medium is installed in a probe head to directly irradiate a sample with the high-power laser [31,32]. Experiments in this mode are presently underway in our group.

Author Contributions: Investigation, R.N., M.S. and H.O.; writing-original draft preparation, R.N.; writing-review and editing, M.S. and H.O.; supervision, H.O. and I.W. All authors have read and agreed to the published version of the manuscript. 
Funding: This research was supported by "Advanced study on remote and in-situ elemental analysis of molten fuel debris in damaged core by innovative optical spectroscopy," the Center of World Intelligence Project for Nuclear S\&T and Human Resource Development, Ministry of Education, Culture, Sports, Science and Technology (MEXT), Japan.

Acknowledgments: The authors wish to thank Masaaki Toshimitsu and Hajime Seito for his technical support in the experiment.

Conflicts of Interest: The authors declare no conflict of interest.

\section{References}

1. Nuclear Damage Compensation and Decommissioning Facilitation Corporation. Technical Strategic Plan 2019 for the Decommissioning of the Fukushima Daiichi Nuclear Power Station of Tokyo Electric Power Company Holdings, Inc.; Nuclear Damage Compensation and Decommissioning Facilitation Corporation: Tokyo, Japan, 2019.

2. Ikeuchi, H.; Ishihara, M.; Yano, K.; Kaji, N.; Nakajima, Y.; Washiya, T. Dissolution behavior of (U, Zr) $\mathrm{O}_{2}$-based simulated fuel debris in nitric acid. J. Nucl. Sci. Technol. 2014, 51, 996-1005. [CrossRef]

3. Nagatani, T.; Komeda, M.; Shiba, T.; Nauchi, Y.; Maeda, M.; Sagara, H.; Kosuge, Y.; Kureta, M.; Tomikawa, H.; Okumura, K. Characterization Study of Four Candidate Technologies for Nuclear Material Quantification in Fuel Debris at Fukushima Daiichi Nuclear Power Station. Energy Procedia 2017, 131, 258-263. [CrossRef]

4. Asou, M.; Porta, J. Prospects for Poisoning Reactor Cores of the Future. Nucl. Eng. Des. 1997, 168, 261-270. [CrossRef]

5. Leinweber, G.; Barry, D.P.; Trbovich, M.J.; Burke, J.A.; Drindak, N.J.; Knox, H.D.; Ballad, R.V.; Block, R.C.; Danon, Y.; Severnyak, L.I. Neutron Capture and Total Cross-Section Measurements and Resonance Parameters of Gadolinium. Nucl. Sci. Eng. 2006, 154, 261-279. [CrossRef]

6. Tognoni, E.; Palleschi, V.; Corsi, M.; Cristoforetti, G. Quantitative Micro-Analysis by Laser-Induced Breakdown Spectroscopy: A Review of the Experimental Approaches. Spectrochim. Acta B At. Spectrosc. 2002, 57, 1115-1130. [CrossRef]

7. Fantoni, R.; Caneve, L.; Colao, F.; Fornarini, L.; Lazic, V.; Spizzichino, V. Methodologies for laboratory laser induced breakdown spectroscopy semi-quantitative and quantitative analysis-A review. Spectrochim. Acta B At. Spectrosc. 2008, 63, 1097-1108. [CrossRef]

8. Bauer, A.J.; Buckley, S.G. Novel applications of laser-induced breakdown spectroscopy. Appl. Spectrosc. 2017, 71, 553-566. [CrossRef]

9. Whitehouse, A.I.; Young, J.; Botheroyd, I.M.; Lawson, S.; Evans, C.P.; Wright, J. Remote material analysis of nuclear power station steam generator tubes by laser-induced breakdown spectroscopy. Spectrochim. Acta B At. Spectrosc. 2001, 56, 821-830. [CrossRef]

10. Barefield, J.E.; Judge, E.J.; Berg, J.M.; Willson, S.P.; Le, L.A.; Lopez, L.N. Analysis and Spectral Assignments of Mixed Actinide Oxide Samples Using Laser-Induced Breakdown Spectroscopy (LIBS). Appl. Spectrosc. 2013, 67, 433-440. [CrossRef]

11. Campbell, K.R.; Wozniak, N.R.; Colgan, J.P.; Judge, E.J.; Barefield, J.E., II; Kilcrease, D.P.; Wilkerson, M.P.; Czerwinski, K.R.; Clegg, S.M. Phase discrimination of uranium oxides using laser-induced breakdown spectroscopy. Spectrochim. Acta B At. Spectrosc. 2017, 134, 91-97. [CrossRef]

12. Campbell, K.R.; Judge, E.J.; Barefield, J.E.; Colgan, J.P.; Kilcrease, D.P.; Czerwinski, K.R.; Clegg, S.M. Laser-induced breakdown spectroscopy of light water reactor simulated used nuclear fuel: Main oxide phase. Spectrochim. Acta B At. Spectrosc. 2017, 133, 26-33. [CrossRef]

13. Fortes, F.J.; Laserna, J.J. The development of fieldable laser-induced breakdown spectrometer: No limits on the horizon. Spectrochim. Acta B At. Spectrosc. 2010, 65, 975-990. [CrossRef]

14. Saeki, M.; Iwanade, A.; Ito, C.; Wakaida, I.; Thornton, B.; Sakka, T.; Ohba, H. Development of a Fiber-Coupled Laser-Induced Breakdown Spectroscopy Instrument for Analysis of Underwater Debris in a Nuclear Reactor Core. J. Nucl. Sci. Technol. 2014, 51, 930-938. [CrossRef]

15. Matsumoto, A.; Ohba, H.; Toshimitsu, M.; Akaoka, K.; Ruas, A.; Sakka, T.; Wakaida, I. Fiber-Optic Laser-Induced Breakdown Spectroscopy of Zirconium Metal in Air: Special Features of The Plasma Produced by A Long-Pulse Laser. Spectrochim. Acta B At. Spectrosc. 2018, 142, 37-49. [CrossRef] 
16. Matsumoto, A.; Ohba, H.; Toshimitsu, M.; Akaoka, K.; Ruas, A.; Wakaida, I.; Sakka, T.; Yae, S. Enhancement of Molecular Formation in Fiber-Optic Laser Ablation with a Long Nanosecond Pulsed Laser. Spectrochim. Acta B At. Spectrosc. 2019, 155, 56-60. [CrossRef]

17. Ye, B.; Oaks, A.; Kirk, M.; Yun, D.; Chen, W.-Y.; Holtzman, B.; Stubbins, J.F. Irradiation Effects in $\mathrm{UO}_{2}$ and CeO2. J. Nucl. Mater. 2013, 441, 525-529. [CrossRef]

18. Williams, A.N.; Phongikaroon, S. Elemental Detection of Cerium and Gadolinium in Aqueous Aerosol via Laser-Induced Breakdown Spectroscopy. Appl. Spectrosc. 2016, 70, 1700-1708. [CrossRef]

19. Williams, A.; Bryce, K.; Phongikaroon, S. Measurement of Cerium and Gadolinium in Solid Lithium Chloride-Potassium Chloride Salt Using Laser-Induced Breakdown Spectroscopy (LIBS). Appl. Spectrosc. 2017, 71, 2302-2312. [CrossRef]

20. Nagasawa, K.; Tanabe, M.; Yahagi, K. Gamma-Ray-Induced Absorption Bands in Pure-Silica-Core Fibers. Jpn. J. Appl. Phys. 1984, 23, 1608-1613. [CrossRef]

21. Deparis, O.; Megret, P.; Decreton, M.; Blondel, M. Gamma Radiation Tests of Potential Optical Fiber Candidates for Fibroscopy. IEEE Trans. Nucl. Sci. 1996, 43, 3027-3031. [CrossRef]

22. Girard, S.; Kuhnhenn, J.; Gusarov, A.; Brichard, B.; Van Uffelen, M.; Ouerdane, Y.; Boukenter, A.; Marcandella, C. Radiation Effects on Silica-Based Optical Fibers: Recent Advances and Future Challenges. IEEE Trans. Nucl. Sci. 2013, 60, 2015-2036. [CrossRef]

23. Choi, D.; Han, B.-Y.; Park, S.H.; Kim, H.-d.; Park, G.-I.; Ku, J.-H. Effect of Radiation on the Transmission Rate of Emission Intensity of Optical Fiber Cable Used in a Nuclear Material Facility. Nucl. Technol. 2017, 197, 320-328. [CrossRef]

24. Girard, S.; Alessi, A.; Richard, N.; Martin-Samos, L.; De Michele, V.; Giacomazzi, L.; Agnello, S.; Francesca, D.D.; Morana, A.; Winkler, B.; et al. Overview of Radiation Induced Point Defects in Silica-Based Optical Fibers. Rev. Phys. 2019, 4. [CrossRef]

25. NIST Atomic Spectra Database (Version 5.7). Available online: https://www.nist.gov/pml/atomic-spectradatabase (accessed on 25 September 2020).

26. Kurucz, R.L.; Bell, B. Atomic Line Data (Kurucz CD-ROM No. 23), Smithsonian Astrophysical Observatory, Cambridge, Mass. 1995. Available online: https://www.cfa.harvard.edu/amp/ampdata/kurucz23/sekur.html (accessed on 25 September 2020).

27. Davies, C.M.; Telle, H.H.; Montgomery, D.J.; Corbett, R.E. Quantitative Analysis Using Remote Laser-Induced Breakdown Spectroscopy (LIBS). Spectrochim. Acta B At. Spectrosc. 1995, 50, 1059-1075. [CrossRef]

28. Ciucci, A.; Corsi, M.; Palleschi, V.; Rastelli, S.; Salvetti, A.; Tognoni, E. New Procedure for Quantitative Elemental Analysis by Laser-Induced Plasma Spectroscopy. Appl. Spectrosc. 1999, 53, 960-964. [CrossRef]

29. Tognoni, E.; Cristoforetti, G.; Legnaioli, S.; Palleschi, V. Calibration-Free Laser-Induced Breakdown Spectroscopy: State of the art. Spectrochim. Acta B At. Spectrosc. 2010, 65, 1-14. [CrossRef]

30. Sakai, H.; Kan, H.; Taira, T. $>1$ MW peak power single-mode high-brightness passively Q-switched $\mathrm{Nd}^{3+}$ : YAG microchip laser. Opt. Express 2008, 16, 19891-19899. [CrossRef]

31. Hartzler, D.A.; Jain, J.C.; McIntyre, D.L. Development of a Subsurface LIBS Sensor for In Situ Groundwater Quality Monitoring with Applications in $\mathrm{CO}_{2}$ Leak Sensing in Carbon Sequestration. Sci. Rep. 2019, 9, 4430. [CrossRef]

32. Tamura, K.; Ohba, H.; Saeki, M.; Taguchi, T.; Lim, H.H.; Taira, T.; Wakaida, I. Development of a Laser-Induced Breakdown Spectroscopy System Using a Ceramic Micro-Laser for Fiber-Optic Remote Analysis. J. Nucl. Sci. Technol. 2020, 1-10. [CrossRef]

Publisher's Note: MDPI stays neutral with regard to jurisdictional claims in published maps and institutional affiliations.

(C) 2020 by the authors. Licensee MDPI, Basel, Switzerland. This article is an open access article distributed under the terms and conditions of the Creative Commons Attribution (CC BY) license (http://creativecommons.org/licenses/by/4.0/). 